\title{
Older people's knowledge of the purpose of drugs prescribed at primary care appointments
}

\author{
Romana Santos Gama ${ }^{1}$, Luiz Carlos Passos $^{1}$, Welma Wildes Amorim², Renato Morais \\ Souza $^{3}$, Hévila Maciel Queiroga ${ }^{4}$, Jessica Caline Macedo ${ }^{3}$, Larissa Gusmão de Oliveira \\ Nunes $^{5}$, and Márcio Galvão Oliveira ${ }^{6}$ \\ ${ }^{1}$ Universidade Federal da Bahia \\ ${ }^{2}$ Universidade Estadual do Sudoeste da Bahia \\ ${ }^{3}$ UFBA \\ ${ }^{4}$ Hospital Santa Izabel \\ ${ }^{5}$ Popular Pharmacy \\ ${ }^{6}$ Instituto Multidisciplinar em Saúde, Universidade Federal da Bahia
}

April 27, 2021

\begin{abstract}
Rationale, aims and objectives: Patient adherence to medication is related to successful pharmacotherapy; however, many patients do not take their medications as prescribed because of poor understanding of their purpose.This study aimed to assess older people's knowledge of the purpose of drugs prescribed at medical appointments in primary care units and the possible factors related to their level of knowledge about their medications. Method: This was a cross-sectional study conducted in 22 basic health units in Brazil. Older people from this sample who were treated in a primary care setting were interviewed after a consultation with a family practice physician. Data were collected from September 2016 to March 2019. Patients aged [?] 60 years who visited the primary care units were included in the study $(\mathrm{n}=674)$. Knowledge of prescribed medications was assessed by comparing the responses to the questionnaire and the medication and prescription information. Multivariate analyses were conducted using a Poisson regression with robust variance. Results: The mean age of the sample was 70.1 (standard deviation: \pm 7.1 ) years. Among 674 patients, $272(40.4 \%)$ did not know the indication of at least one of their prescribed drugs; among them $78(11.6 \%)$ did not know the indication of any of their prescribed drugs. In the final multivariate analysis, polypharmacy, illiteracy, and cognitive impairment were found to be associated with misunderstanding the purpose of at least one prescribed drug. Moreover, illiteracy and cognitive impairment were associated with a greater misunderstanding of the purpose of all prescribed drugs. Conclusions: In the studied sample, patients demonstrated a high rate of misunderstanding of the purpose of prescribed drugs. Therefore, it is necessary for health services and professionals to implement strategies that increase the quality of the guidance and instructions given to older people in order to promote adherence to treatment.
\end{abstract}

\section{Hosted file}

Manuscript_1504.pdf available at https://authorea.com/users/410347/articles/519832-olderpeople-s-knowledge-of-the-purpose-of-drugs-prescribed-at-primary-care-appointments 